\title{
Os cientistas e os meios de comunicação de massa: um estudo de caso no Instituto Oswaldo Cruz
}

\author{
Scientists and the mass media: a case study at the Instituto Oswaldo Cruz \\ Los científicos y los medios de comunicación masivos: un estudio de caso \\ en el Instituto Oswaldo Cruz
}

\author{
Bárbara Ávila Maia | barbara.avila.maia@gmail.com \\ Fundação Oswaldo Cruz, Instituto Oswaldo Cruz. Rio de Janeiro, Brasil. \\ Luiza Massarani | luisa.massarani5@gmail.com \\ Fundação Oswaldo Cruz, Casa de Oswaldo Cruz. Rio de Janeiro, Brasil.
}

\section{Resumo}

Este artigo apresenta um estudo de caso sobre a relação dos cientistas do Instituto Oswaldo Cruz (IOC) com os meios de comunicação de massa e com a divulgação científica em geral. O Instituto é uma das unidades da Fundação Oswaldo Cruz (Fiocruz), localiza-se no Rio de Janeiro (Brasil), e é reconhecido internacionalmente por sua relevante produção científica na área da saúde. O estudo foi realizado por meio de uma enquete online, respondida por 103 cientistas de um universo de 487 pesquisadores e tecnologistas do IOC, e 20 entrevistas semiestruturadas feitas com stakeholders. Os resultados indicam um processo de crescente divulgação da ciência no Instituto, em contato relativamente frequente com a mídia e uma adesão às ações voltadas para o público promovidas pelo IOC. Por outro lado, identificamos poucas iniciativas próprias de divulgação científica por meio de blogs e redes sociais.

Palavras-chave: divulgação científica; comunicação pública da ciência; meio de comunicação de massa; cientista; jornalista.

\begin{abstract}
This article presents a case study about the relationship between the scientists of IOC - Instituto Oswaldo Cruz (Oswaldo Cruz Institute) and the mass media as well as their science diffusion in general. The Institute is one of the units of the Fiocruz - Fundação Oswaldo Cruz (Oswaldo Cruz Foundation), located in Rio de Janeiro (Brazil), and it is internationally recognized for its relevant scientific production in health. The study was conducted through an online survey, answered by 103 scientists from a universe of 487 researchers and technologists members of IOC staff, and 20 semi-structured interviews with stakeholders. The results indicate a growing process of science dissemination in the Institute, relatively frequent contact with the media and compliance in relation to actions aimed at the public promoted by IOC. On the other hand, we have identified few own initiatives of science diffusion through blogs and social networks.
\end{abstract}

Keywords: science diffusion; public communication of science; mass media; scientist; journalist. 


\section{Resumen}

Este artículo presenta un estudio de caso sobre la relación de los científicos del Instituto Oswaldo Cruz (IOC) con los medios masivos de comunicación y con la divulgación científica en general. El Instituto es una de las unidades de la Fiocruz - Fundação Oswaldo Cruz (Fundación Oswaldo Cruz), se ubica en Rio de Janeiro (Brasil) y es reconocido internacionalmente por su relevante producción científica en salud. El estudio fue realizado a través de una encuesta en línea, respondida por 103 científicos de un universo de 487 investigadores y tecnólogos del IOC, y 20 entrevistas semiestructuradas hechas con stakeholders. Los resultados indican un creciente proceso de divulgación de la ciencia en el Instituto, contacto relativamente frecuente con la prensa y adhesión a las acciones dirigidas al público promovidas por el IOC. Por otro lado, identificamos pocas iniciativas propias de divulgación científica a través de blogs y redes sociales.

Palabras clave: divulgación científica; comunicación pública de la ciencia; medio de comunicación masivo; científico; periodista.

Contribuição dos autores: Ambas as autoras contribuíram com todas as etapas de preparação do artigo (concepção e desenho do estudo; aquisição e análise ou interpretação dos dados; redação do manuscrito; revisão crítica do conteúdo intelectual).

Declaração de conflito de interesses: As autoras afirmam não haver conflito de interesses.

Fontes de financiamento: Conselho Nacional de Desenvolvimento Científico e Tecnológico (CNPq).

Considerações éticas: O estudo foi aprovado pelo Comitê de Ética em Pesquisa com Seres Humanos (CEP) da Escola Politécnica de Saúde Joaquim Venâncio/Fiocruz, sob Certificado de Apresentação para Apreciação Ética (CAAE) de número 46058515.9.0000.5241 e parecer de número 1.168.288.

Agradecimento/Contribuições adicionais: Agradecemos ao Dr. Hans Peter Peters pela grande contribuição teórica e metodológica para o desenvolvimento desta investigação e aos cientistas do IOC que, gentilmente, participaram das etapas de coleta de dados.

Histórico do artigo: Submetido: 28.jun.2017 | Aceito: 16.ago.2017 | Publicado: 29.dez.2017

Licença CC BY-NC atribuição não comercial. Com essa licença é permitido acessar, baixar (download), copiar, imprimir, compartilhar, reutilizar e distribuir os artigos, desde que para uso não comercial e com a citação da fonte, conferindo os devidos créditos de autoria e menção à Reciis. Nesses casos, nenhuma permissão é necessária por parte dos autores ou dos editores. 


\section{Introdução}

A relevância da divulgação científica está atrelada ao importante papel que a ciência representa no mundo atual. Field e Powell ${ }^{1}$ ressaltam como o grande aumento no número de estudos e experimentos científicos pode ter profundo impacto na vida de cidadãos de diferentes nações. Entretanto, os autores apontam que são poucas as pessoas que têm consciência de como e por que uma pesquisa é conduzida, além de compreenderem suas potenciais implicações.

De acordo com Lewenstein², a expressão "ciência e mídia" engloba duas grandes instituições sociais. O autor define a primeira não só como um sistema de conhecimento confiável sobre o mundo natural, mas também como um complexo sistema social de desenvolvimento e manutenção desse conhecimento. De forma semelhante, a mídia, entendida como as estruturas integrais dos principais meios de comunicação de massa, compreende um sistema variado de coleta e apresentação de informações, além de ter impactos econômicos, políticos e sociais significativos. Assim, a relação entre ciência e mídia, ao longo da história, é marcada pelo crescimento progressivo do uso da mídia pela ciência, da atenção às ideias científicas pelas instituições midiáticas e das tensões causadas pelo aumento dessa interação.

Essa união entre ciência e mídia é a base para a tese da "midialização da ciência", que, segundo Weingart ${ }^{3}$, consiste no aumento crescente da orientação da ciência pela mídia. O autor aponta que um primeiro motivo para esse fenômeno seria o crescimento da importância da mídia na formação da opinião, consciência e percepção públicas. Além disso, outro fator que colabora para esse quadro é a dependência de investimentos financeiros, muitas vezes escassos, apresentada pela ciência, o que estimula uma busca da aceitação pública. Assim, a midialização do conhecimento científico pode não só influenciar as agendas políticas governamentais, mas também é capaz de interferir na mobilização de recursos econômicos em escalas nacionais e internacionais.

Estudos realizados em diferentes países revelam indicações empíricas de que eles apoiam a ideia da midialização da ciência. Entre elas está o alto valor que cientistas e centros de pesquisa e ensino têm dado à divulgação da ciência por meio da mídia. Outro indício seria a institucionalização do contato com os meios de comunicação de massa e sua vinculação aos papéis de liderança. Por fim, a adoção de uma lógica midiática para a autorrepresentação da ciência resulta em uma construção de relevância baseada em referências não científicas e geração de notícias segundo os critérios da mídia

Essa importância intensificada da mídia não só para a ciência, mas para a cultura em geral, é denominada “midiatização" por alguns autores. Segundo Hjarvard5, a midiatização é um processo em que a sociedade passa a demonstrar uma dependência, cada vez maior, da mídia e da sua lógica. Ainda de acordo com o autor, os meios de comunicação não só integram as operações de diferentes instituições, mas também adquirem o status de instituição social em pleno direito, tornando-se fundamental para as interações sociais.

Dessa forma, é importante esclarecer o que entendemos como "meio de comunicação de massa", que seriam jornais, revistas, televisão, rádios e suas respectivas versões online. Optamos por adotar a definição de Potter ${ }^{6}$, que descreve de forma minuciosa as características desses meios. Segundo o autor, o remetente das mensagens é uma organização ou instituição complexa, não um indivíduo, que usa práticas padronizadas para produzir e disseminar conteúdo em massa. Além disso, essa organização tem consciência dos diferentes nichos que compõem seu público, esforçando-se para atrair o maior número possível de interessados com exposições repetidas de forma habitual.

Em relação aos membros da audiência dos meios de comunicação de massa, Potter ${ }^{6}$ aponta que eles se encontram geograficamente dispersos e que têm consciência do caráter público e automatizado das mensagens que recebem. Por fim, o autor descreve os canais de disseminação como dispositivos tecnológicos que tornam as mensagens acessíveis a todos e têm a possibilidade de ampliar a disponibilidade do conteúdo no tempo e no espaço, alcançando o público, até mesmo, simultaneamente. 
Também é importante ressaltar o impacto da era digital na comunicação, com foco para a revolução da web 2.0, que possibilita a colaboração entre os usuários no que diz respeito à produção e ao acesso aos conteúdos. Assim, as mídias tradicionais, como jornais e revistas impressos, buscaram se adaptar e passaram a integrar a internet, por meio do fornecimento de conteúdo e interação em plataformas online. Além disso, por conta da existência de dispositivos móveis acessíveis a um público bastante amplo, o contato com a informação passa a ser, praticamente, instantâneo, o que aproxima a internet da onipresença. Dessa forma, ao oferecerem canais e formatos de comunicação alternativos, as novas mídias podem transformar, em longo prazo, a interface entre ciência e sociedade

Assim, diante da relevância dos meios de comunicação de massa e da internet para a divulgação da ciência, a aproximação entre as culturas científica e jornalística torna-se cada vez mais frequente. Para exemplificar essa tendência, podemos citar a organização de assessorias de imprensa ou de comunicação em centros de pesquisa e universidades. Esse setor pode exercer influência na forma de veiculação do conhecimento científico, funcionando como um elo entre a instituição de pesquisa e a mídia. Geralmente, os profissionais que trabalham como assessores de imprensa têm como público outros jornalistas, integrantes de redações de meios de comunicação, que, só depois desse contato, escrevem para o público geral ${ }^{8}$.

Diante do panorama traçado até aqui, esta investigação teve como objetivo analisar a relação dos cientistas do Instituto Oswaldo Cruz (IOC), unidade da Fundação Oswaldo Cruz (Fiocruz), com os meios de comunicação de massa, bem como a sua inserção na área da divulgação científica de uma maneira geral. Localizado no campus de Manguinhos, na cidade do Rio de Janeiro, Rio de Janeiro, Brasil, o IOC é reconhecido nacional e internacionalmente, apresentando como missão ${ }^{1}$ a realização de pesquisa, ensino, desenvolvimento tecnológico, inovação, serviços de referência e de coleções biológicas, com o objetivo principal de promover a saúde.

Conhecer a história do $\mathrm{IOC}^{9}$ é conhecer também importantes acontecimentos que marcaram fortemente o cenário da ciência brasileira. Em 1900, foram iniciadas as atividades do Instituto Soroterápico, localizado na Fazenda de Manguinhos e dirigido por Oswaldo Cruz. Além do sucesso na produção do soro e da vacina contra a peste bubônica, pesquisas relevantes realizadas por cientistas do Instituto, em diferentes áreas, passaram a ser reconhecidas e premiadas internacionalmente. Dessa forma, devido à realização de atividades que extrapolavam a fabricação de soros e vacinas, Oswaldo Cruz e os outros pesquisadores passam denominar o centro de pesquisa de Instituto de Manguinhos.

Diante dessa relevância, o projeto que transformava o Instituto Soroterápico Federal em "Instituto de Patologia Experimental", que estava adormecido no Congresso, foi aprovado e sancionado pelo presidente Affonso Penna, pelo Decreto $\mathrm{n}^{\circ}$ 1812, em 12 de dezembro de 1907. Após a aprovação do regimento pelo governo federal, em 19 de março de 1908, a denominação "Instituto Oswaldo Cruz" passou a ser oficialmente adotada ${ }^{9}$. Mais tarde, em maio de 1970, outro decreto federal ${ }^{2}$ determinou a criação da Fundação Oswaldo Cruz (Fiocruz).

O IOC passou, então, a integrar a Fiocruz, juntamente com outros centros de pesquisa importantes, entre eles a Escola Nacional de Saúde Pública, o Instituto Fernandes Figueira e o Instituto Evandro Chagas ${ }^{11}$. Atualmente, um total de 16 unidades técnico-científicas integram a Fundação, que agora está presente não só no Rio de Janeiro, mas em mais nove estados do Brasil, entre eles Amazonas, Bahia e Minas Gerais. Além disso, a Fiocruz também apresenta um escritório na África, em Maputo, a capital do Moçambique9.

A relevância da produção do Instituto pode ser comprovada por meio do relatório científico do ano de 2015, divulgado pela gestão do IOC. Além dos 535 artigos publicados em revistas indexadas de circulação internacional, foram numerosas as teses e dissertações de pós-graduação e as palestras e conferências ministradas pelos pesquisadores vinculados ao IOC. O relatório também destaca "o fato de o Instituto ter dado respostas rápidas e importantes no que diz respeito à emergência em saúde pública de relevância nacional, relacionada à infecção congênita pelo vírus Zika"12. 
Simultaneamente às atividades de pesquisa, o IOC investe em iniciativas de ensino, colaborando com a formação de recursos humanos nas áreas de biociências e saúde. Segundo o Guia do aluno ${ }^{13}$ do IOC, mais de 100 pesquisadores do Instituto estão envolvidos com a formação acadêmica de cerca de mil estudantes, colaborando com a produção de conhecimento científico e inovação para a saúde pública do Brasil.

Sobre o relacionamento do Instituto com a mídia, destaca-se a atuação do Serviço de Jornalismo e Comunicação (Sejor/IOC). O Sejor/IOC não só promove a comunicação interna, mas também atua como intermediário na relação dos cientistas com a população. Sua principal função é "desenvolver ações que aproximam o conhecimento científico da sociedade, ao mesmo tempo em que busca garantir visibilidade para as atividades do Instituto" ${ }^{14}$.

Segundo dados fornecidos pelo próprio Sejor/IOC, nos anos de 2013 e 2014, um total de 1.395 publicações sobre o IOC foi veiculado pela imprensa, estando incluídas nesse número publicações que apresentam cientistas do Instituto como fonte de informação. $\mathrm{O}$ ano de 2015 também contou com grande participação do IOC na mídia, tendo sido publicadas 604 reportagens sobre o Instituto na imprensa ${ }^{14}$. Apesar de ainda não terem sido divulgados os dados referentes às interações com a imprensa durante o ano de 2016, é possível afirmar que as aparições de profissionais do Instituto na mídia se mantiveram frequentes, principalmente devido à repercussão dos resultados de pesquisas de grande impacto para a saúde pública que foram desenvolvidas nesse período. Como destaque, podemos citar as contribuições científicas $^{15}$ do IOC relacionadas ao vírus Zika, entre elas o primeiro sequenciamento genético completo desse vírus causador da doença, ligado a um caso de microcefalia no Brasil, isolado a partir do líquido amniótico de uma gestante ${ }^{16}$.

Diante disso, podemos dizer que o IOC é uma fonte de informações confiáveis para a mídia, quando o assunto é saúde pública. Dessa forma, fica clara a relevância que o Instituto representa não só para a ciência brasileira, mas também para o cenário científico internacional. Investigar a relação dos cientistas do IOC com a imprensa pode trazer grandes contribuições para entender como a divulgação da ciência produzida nesse centro de pesquisa vem sendo realizada pelos meios de comunicação de massa.

\section{Estratégia metodológica}

Este artigo apresenta uma pesquisa descritiva sobre a relação dos cientistas do IOC com os meios de comunicação de massa e com a divulgação em geral. O estudo de caso integra um projeto de maior escopo, de âmbito nacional, fruto da parceria entre o Núcleo de Estudos da Divulgação Científica (NEDC) do Museu da Vida/Casa de Oswaldo Cruz/Fiocruz, Brasil, com o Centro de Pesquisa Jülich, Alemanha, em particular com o Dr. Hans Peter Peters. Peters é um dos nomes mais reconhecidos, mundialmente, por investigações que seguem a linha na qual se insere esta pesquisa, sendo responsável por projetos similares realizados em diferentes países. Financiado pelo CNPq, o objetivo principal do projeto nacional ${ }^{17}$ consistiu em analisar como cientistas brasileiros, oriundos de diferentes regiões do país, se relacionam com os meios de comunicação de massa, por meio de uma enquete online respondida por 956 pesquisadores associada a 20 entrevistas qualitativas de aprofundamento.

O estudo de caso no IOC incluiu duas etapas de coleta de dados. Primeiramente, um questionário online foi enviado por e-mail a 487 pesquisadores e tecnologistas que atuam nos 72 laboratórios do Instituto. Para isso, visitamos a página do $\mathrm{IOC}^{18}$ na internet e, na aba "Pesquisa", localizada à esquerda da tela, buscamos por "Laboratórios" ${ }^{19}$. Na página de cada laboratório, também à esquerda, o link para "Equipe e contato" apresenta a listagem dos nomes de todos os integrantes. Optamos por selecionar os nomes classificados nos seguintes cargos: chefe de laboratório, chefe substituto de laboratório, corpo de pesquisa, corpo técnico e colaboradores. Nomes de bolsistas e estudantes não entraram na lista dessa pesquisa. A busca pelos 
correios eletrônicos pessoais de cada cientista foi feita na plataforma webmail $\mathrm{IOC}^{20}$. Na aba "Contatos" ${ }^{3}$ é possível buscar o endereço de e-mail institucional a partir do nome completo do pesquisador.

O questionário foi desenvolvido com base em investigações anteriores realizadas por Peters ${ }^{22,23} \mathrm{e}$ colaboradores $^{24}$, traduzido para o português e adaptado à realidade brasileira em estudo similar de alcance nacional ${ }^{17}$. Respondido de forma anônima e composto por 36 questões, é necessário um tempo de aproximadamente 20 minutos para respondê-lo por completo. As perguntas buscam delinear o perfil do respondente e as suas percepções sobre a relação de cientistas com os meios de comunicação de massa. Esse instrumento de coleta de dados foi elaborado na plataforma Formulários Google ${ }^{25}$. O convite para que os pesquisadores do IOC participassem da investigação foi enviado por e-mail, com uma mensagem assinada pelas pesquisadoras responsáveis. O questionário online ficou disponível para o recebimento de respostas desde 18 de abril até 04 de julho de 2016, ou seja, permaneceu por cerca de três meses e meio no ar.

No total, dos 487 cientistas que receberam a mensagem eletrônica, 106 responderam à enquete, o que resulta em uma porcentagem de respostas de $21,8 \%$. Esse dado deve ser visto com cuidado, pois o número 487 não significa, necessariamente, que todos sejam pesquisadores do IOC - alguns deles, por exemplo, podem já ter se desvinculado desse Instituto. Ilustrativo é o fato de que três pessoas que receberam o e-mail convite e se dispuseram a responder ao questionário não se enquadraram nos pré-requisitos estabelecidos: "ser cientista" e "apresentar vínculo com o IOC". Com isso, o número de respostas válidas foi de 103, pois um deles alegou não desenvolver atividades de pesquisa no Instituto, enquanto os outros dois não se autodeclararam cientistas.

Os dados quantitativos coletados nessa etapa foram analisados com o software SPSS - Statistical Package for the Social Sciences. Apesar de apresentar uma plataforma de fácil compreensão, esse programa é uma ferramenta potente para o tratamento de dados e análises estatísticas ${ }^{4}$. Esse software também foi utilizado na análise dos resultados obtidos na pesquisa nacional realizada por Massarani e Peters ${ }^{17}$, na qual este estudo se insere.

A segunda etapa, de caráter qualitativo, consistiu na realização de 20 entrevistas semiestruturadas com stakeholdersi do Instituto. A escolha dos nomes dos entrevistados e a elaboração dos roteiros para elaboração das perguntas foram baseadas nos resultados da etapa quantitativa. Entre os critérios de seleção, buscamos estabelecer um equilíbrio de sexo, faixa etária, atuação em cargos de chefia ou não, análise da aba "Educação e Popularização da C\&T" do Currículo Lattes e o número de contatos com a mídia declarado no questionário online.

Também foram entrevistados alguns responsáveis pelas tomadas de decisão, para compreendermos a cultura institucional na área, a saber: a vice-presidente de Ensino, Informação e Comunicação da Fiocruz na época, Nísia Trindade Lima; o diretor do IOC, Wilson Savino; a vice-diretora de Ensino, Informação e Comunicação do IOC, Elisa Cupolillo, e a coordenadora do Serviço de Jornalismo e Comunicação do IOC (Sejor/IOC), Raquel Aguiar.

Ao citar alguns depoimentos neste artigo, optamos por manter a identidade dos participantes em sigilo. Essa decisão foi tomada com o objetivo de preservar as opiniões pessoais dos envolvidos. Escolhemos o codinome "Cientista", seguido da numeração de 1 a 4, para identificar trechos retirados de quatro entrevistas distintas. Revelamos, apenas, a autoria de falas de Elisa Cupolillo e de Raquel Aguiar que apresentaram esclarecimentos sobre políticas e ações institucionais.

Duas das entrevistas aconteceram nos meses de novembro e dezembro de 2015. As outras 18 foram realizadas durante o mês de outubro de 2016. Todas foram feitas pessoalmente por uma das responsáveis deste estudo, Bárbara Ávila Maia, na época, estudante de mestrado do Programa de Pós-graduação Stricto

\footnotetext{
Adotamos o significado de stakeholder proposto pelo Dicionário Cambridge, em que o termo traduzido do inglês para o português é "parte interessada" e seu significado pode ser compreendido como "Uma pessoa, como um funcionário, cliente ou cidadão, envolvido com uma organização, sociedade, etc. e, portanto, tem responsabilidades para com isso e interesse em seu sucesso".
} 
sensu em Ensino em Biociências e Saúde do IOC. O tempo médio de duração das entrevistas foi de 49 minutos e 24 segundos. Para posterior análise de dados, as conversas foram gravadas e mapeadas, recebendo indicações dos temas discutidos segundo os minutos e segundos da gravação. Após esse mapeamento, de acordo com a sistematização proposta por Alves e Silva ${ }^{5}$, trechos selecionados foram transcritos e relacionados com os dados da etapa quantitativa.

\section{Resultados e discussão}

\section{Perfil dos participantes}

Primeiramente, entre os 103 cientistas que responderam ao questionário online, 54,4\% são do sexo feminino e 45,6\% do sexo masculino. A faixa etária dos participantes é ampla, sendo a idade mínima 29 anos e a máxima 80 anos. No entanto, grande parte se concentra na faixa de 40 a 59 anos de idade: 31,5\% dos pesquisadores têm entre 50 e 59, e $28,2 \%$ entre 40 e 49 . Muitos dos participantes exercem algum papel de gestão no IOC e quase metade (46,5\%) assume a função de líder de grupo ou de investigador principal.

Os participantes também apresentam altas qualificação e produção científica. A maior parte dos respondentes da enquete $(89,3 \%)$ declarou que seu grau acadêmico mais avançado é "PhD, Doutor (a) (ou equivalente)". Quando perguntados sobre o total de artigos acadêmicos ou capítulos de livros publicados como autor ou coautor durante a carreira científica, 31,1\% declararam ter entre 10 e 25 publicações, enquanto $26,2 \%$ apontaram ter de 26 a 50. Uma parcela de 17,5\% publicou de 51 a 100 artigos ou capítulos, enquanto outros 12,6\% declararam apresentar uma elevada produção acadêmica, com mais de 100 publicações desse tipo.

Dentre os que concederam a entrevista, havia 12 mulheres e 8 homens, com faixa etária variada, tendo o mais novo nascido em 1980 e o mais velho em 1936. Dezesseis eram cientistas que participaram da primeira etapa de coleta de dados, respondendo ao questionário online. A partir dos dados fornecidos e da análise do Currículo Lattes, convidamos pesquisadores com diferentes graus de envolvimento com a divulgação científica para essa segunda etapa. Como citado na estratégia metodológica, os outros quatros participantes entrevistados ocupavam cargos de liderança no IOC e responderam a algumas perguntas sobre a política institucional acerca do tema investigado.

\section{Relacionamento com a mídia: condições e expectativas}

Quando perguntados sobre a política do IOC diante da divulgação de pesquisas na mídia, $61,2 \%$ dos cientistas que responderam ao questionário online afirmaram que, em geral, o Instituto apresenta uma postura positiva diante desse tipo de ação. Entretanto, durante as entrevistas de aprofundamento, nove pesquisadores revelaram que a política institucional a favor da divulgação da ciência ainda está em fase de desenvolvimento no IOC, sendo que quatro destes declararam que o Instituto apresenta pouco ou nenhum estímulo para que eles possam divulgar seu trabalho para a população.

A forte tradição que o Instituto tem na pesquisa laboratorial de bancada, com comunicação voltada para pares, pode ser um fator que dificulte o estímulo da gestão e o estabelecimento de uma cultura de divulgação científica entre os pesquisadores. Além disso, a fase de consolidação de políticas voltadas para o favorecimento da divulgação científica dentro do IOC pode ainda estar em andamento, devido ao fato de as exigências do governo brasileiro e de as agências de fomento em relação à cobrança desse tipo de iniciativa serem recentes no cenário científico do país.

Outro resultado de destaque diz respeito à realização de consultas prévias a superiores e departamentos, caso os cientistas do IOC queiram falar com algum jornalista. Quase metade dos respondentes (48,5\%) indicou que a consulta ao responsável pela assessoria de imprensa do IOC, que corresponderia à equipe 
do Serviço de Jornalismo e Comunicação (Sejor/IOC), é sempre exigida. A consulta a líderes de projeto de pesquisa ou a gestores foi indicada por $35,9 \%$ dos respondentes como exigida em todos os momentos. Um dos entrevistados revelou ter recebido a seguinte orientação quando passou a integrar o corpo de pesquisadores do Instituto:

Assim que eu entrei aqui, coisas me foram ditas que a gente podia e não podia, e uma delas é o seguinte: que entrevista só seja dada depois que passar pelo Setor de Comunicação. Porque a Fiocruz tem um nome, né? Então, qualquer coisa que você falar: 'Ah, um pesquisador da Fiocruz falou isso, falou aquilo, falou aquilo outro, aquilo tem um nome...' Depois que cai na internet, é uma coisa que 'nego' copia o trecho que interessa e diz que foi um pesquisador que falou e aí segue adiante. (Cientista 1, 2016)

É importante mencionar que a necessidade de consulta ao Sejor/IOC se refere à política institucional de preparar melhor os cientistas para sua relação com a mídia (e não um fator de controle). O depoimento a seguir, concedido pela coordenadora do Serviço, reforça essa relevância e cita os principais pontos sobre a forma com que esse trabalho é realizado, juntamente com os pesquisadores do Instituto:

Nós somos um serviço de jornalismo e de comunicação. Primeiro, um serviço, porque a gente tá aqui porque a pesquisa existe, porque a referência existe, porque o ensino existe. A gente se entende e acha ótimo ser 'meio', ser uma estrutura 'meio', uma estrutura de apoio. Eu acho que a minha primeira pegada é essa: focar na sinergia, e não no conflito. E, por que que isso é possível? Porque a gente está aqui para profissionalizar esse contato e para dar todas as garantias pro meu pesquisador, para ele ir tranquilo falar com a mídia. [...]

E a segunda grande marca, que eu acho que é fundamental, é: eu entendo comunicação como comunicação integrada. É muito comum, na Fiocruz e nas instituições, de uma forma geral, você ter núcleos de comunicação interna, de assessoria de imprensa, de mídias sociais, desarticulados, muitas vezes. Ou que só no formato tenha articulação e, na prática, eles trabalhem separados. Aqui, eu trabalho de uma forma integrada mesmo. (Raquel Aguiar, 2016)

Nesse quesito, uma grande diferença foi constatada no resultado da pesquisa nacional realizada por Massarani e Peters ${ }^{17}$. Os resultados do estudo brasileiro indicaram que a maioria dos pesquisadores participantes (cerca de 70,0\%) não necessita consultar superiores, assessorias de imprensa, colaboradores, financiadores ou outras autoridades para entrar em contato com a mídia. Assim, quando comparado com outros centros de pesquisa brasileiro, o IOC demonstra uma maior preocupação em profissionalizar e orientar o contato entre seus pesquisadores e os profissionais da mídia.

Um resultado que também se destacou tem relação com a iniciativa do contato para divulgar trabalhos científicos na mídia. Mais da metade dos cientistas do IOC que responderam ao questionário online (57,3\%) acham importante que a imprensa faça o contato inicial para a divulgação da sua pesquisa, enquanto uma parcela de 29,1\% disse que essa condição não seria relevante. O estudo nacional com desenho metodológico semelhante ${ }^{17}$ também indicou que, nos últimos contatos apontados pelos cientistas, a maioria dos jornalistas $(77,0 \%)$ teve a iniciativa de procurar os pesquisadores para que eles concedessem entrevistas e, raramente, o contato inicial com a mídia partiu da comunidade científica.

Esse comportamento pode estar relacionado com o fato de que o próprio cientista, ao estar imerso na rotina do laboratório e nos compromissos do meio acadêmico, acaba não percebendo a relevância do seu trabalho e o impacto que a divulgação científica pode trazer para a sociedade. Outra explicação para esse resultado observado no IOC seria a confiança dos seus pesquisadores no trabalho do Sejor/IOC. O Serviço é reconhecido por se inteirar das pesquisas que estão em andamento no Instituto e direcionar os convites aos que as realizam para participá-las à imprensa. Dessa forma, os cientistas acabam se acomodando e não se acostumam a tomar a iniciativa de fazer contatos com a mídia. 


\section{Experiências com a mídia: informações e percepções}

Um resultado relevante da investigação realizada no IOC foi a constatação de uma frequência considerável de contato dos pesquisadores do Instituto com profissionais ligados aos meios de comunicação de massa. Por meio do questionário online, $65,0 \%$ dos participantes declararam ter tido contato com jornalistas nos últimos três anos. Um estudo internacional ${ }^{22}$ liderado por Peters, realizado com cientistas dos Estados Unidos, Japão, Reino Unido, Alemanha e França, apresentou resultado próximo ao que foi observado no Instituto. Cerca de dois terços $(64,0 \%)$ dos pesquisadores participantes disseram que foram entrevistados por jornalistas nos últimos três anos anteriores ao levantamento dos dados.

Algo semelhante foi indicado na pesquisa conduzida por Massarani e Peters no Brasil ${ }^{17}$. Os resultados obtidos também apontaram que os pesquisadores brasileiros têm uma relação próxima com os meios de comunicação. Cerca de 80,0\% dos respondentes da investigação nacional ${ }^{17}$ se relacionaram com a mídia no período de três anos anteriores à pesquisa, porcentagem até mesmo superior ao que foi observado no IOC.

Investigações realizadas ao redor do mundo ${ }^{28,29}$ também indicam que o relacionamento entre cientistas e jornalistas não só é mais frequente, mas também mais amigável do que o senso comum costuma sugerir. No IOC, por exemplo, entre os $65,0 \%$ dos respondentes que declararam ter tido contato com jornalistas no último triênio, 55,4\% descreveram que esse contato foi, em geral, bom. Outros 4,9\% indicaram que experiências boas e ruins ocorreram mais ou menos na mesma proporção, e 3,9\% declararam que o contato foi neutro. Apenas um respondente (1,0\%) assumiu que, em geral, a interação com jornalistas foi ruim.

Para esse mesmo tema, a pesquisa nacional também apresentou respostas positivas. Cerca de dois terços dos participantes descreveram que os contatos com jornalistas ocorridos nos três anos anteriores foram, no geral, bons, e 23,0\% tiveram experiências boas e ruins. Somente 4,0\% dos respondentes reportaram experiências ruins ${ }^{17}$. Esses resultados contribuem para questionar os estereótipos de que os pesquisadores se relacionam com baixa frequência e de maneira pouco amistosa com jornalistas. $\mathrm{O}$ depoimento a seguir também exemplifica esta tendência:

Eu acho que o mundo tende à interdisciplinaridade. E acho que a gente está vivendo isso
nas relaçôes com as pessoas. Por isso, acho que essas coisas de você ter grupos que pensam
diferente trabalhando juntos melhoram, ainda mais, a qualidade dos serviços. Eu acho
que isso tem que se intensificar a cada dia. Eu acho que a gente [cientistas] não pode ficar
no nosso mundinho, nem eles [jornalistas] no mundinho deles, e eles não lendo as coisas
indiretamente, mas sendo parceiros no processo. [...]. Esta relação entre o profissional da
mídia e o profissional da saúde tem que ser mais afinada. (Cientista 2, 2016)

Outro ponto em comum entre o estudo de caso feito no IOC e a pesquisa de alcance nacional ${ }^{17}$ diz respeito à natureza dos meios aos quais pertencem os jornalistas que se relacionam com os cientistas participantes. Observamos que, em ambos os casos, jornalistas de jornais ou revistas/periódicos são os que mais entraram em contato com os pesquisadores. Em segundo lugar, estão os profissionais que trabalham na televisão.

Sobre os impactos do envolvimento com a mídia, os dados obtidos por meio do questionário online indicam que os pesquisadores do Instituto avaliam que as consequências de aparecerem na imprensa para a reputação científica tendem a ser neutras ou positivas. Além disso, cerca de um terço dos cientistas apontou que, em seu último envolvimento com a mídia, no geral, os colegas da comunidade científica reagiram de forma positiva e que não houve sérias consequências profissionais, sejam elas úteis ou prejudiciais. Esse tipo de percepção pode ser consequência do trabalho realizado pelo Sejor/IOC. A profissionalização do contato com os jornalistas pode ajudar a minimizar possíveis atritos e desentendimentos, o que acaba resultando em uma avaliação mais positiva dos pesquisadores em relação às experiências com a imprensa.

Acreditamos que os dados recolhidos por meio do questionário online e das entrevistas de aprofundamento mostram fortes indícios de que os cientistas participantes não só se preocupam, mas, muitas vezes, adotam certas ações pautadas pela influência da mídia na dinâmica da ciência. Dessa maneira, assim como observado 
por Petersen, Heinrichs e Peters ${ }^{30}$, a forma em que se dá o envolvimento dos pesquisadores do IOC com a mídia pode ser reflexo da midialização da ciência produzida no Instituto. Ou então, a midiatização ${ }^{5}$ da ciência também pode explicar esses comportamentos, já que ela é constatada quando os critérios midiáticos passam a apresentar relevância considerável dentro do cenário social em que o meio científico se encontra inserido.

Além da considerável frequência de contato entre os cientistas participantes e a imprensa, outros indícios de aproximação podem ser observados nas experiências da comunidade científica do IOC com a mídia. Entre eles podemos citar a atuação ativa e sistematizada do Sejor/IOC, que apresenta grande relevância dentro do Instituto. Além disso, é perceptível a importância dada, pela gestão do Instituto e por seus pesquisadores, à exposição do IOC na imprensa e a preocupação dos cientistas diante das consequências profissionais e políticas trazidas pelo envolvimento com os meios de comunicação de massa. O depoimento a seguir, que explica o porquê da importância de o cientista apoiar publicamente questões que favoreçam o financiamento e o desenvolvimento da ciência no Brasil, ilustra um assunto recorrente nas entrevistas de aprofundamento, reforçando esse ponto de vista:

Agora, claro que, inevitavelmente... Por que uma questão política? Por que uma questão econômica? Porque você tem um financiamento para a pesquisa. A política nacional da ciência. Quer dizer, então, isso talvez seja muito mais atrelado, vamos dizer, diretamente atrelado. Eu acho que também pode ser uma expectativa de saber qual é o posicionamento que o pesquisador tem frente a essas políticas científicas no país [...]. (Cientista 3, 2016)

Dessa forma, os resultados demonstram que muitos participantes desta pesquisa concordam que a orientação da ciência pela mídia pode contribuir para dar mais visibilidade e credibilidade para o meio científico diante do sistema político-administrativo, assim como já observado por Peters e outros ${ }^{31}$. Segundo o autor alemão e seus colaboradores, os efeitos da midialização da ciência são vistos como uma contribuição para a legitimação da própria ciência, reforçando a percepção da sua relevância social e melhorando as possibilidades do conhecimento científico se tornar efetivo na formulação de políticas.

\section{Divulgação científica em geral: envolvimento com atividades diversas e consequências para o público}

A análise dos resultados obtidos nos permitiu observar que, muitas vezes, o comprometimento dos pesquisadores participantes com a comunicação dos resultados dentro do próprio meio científico pode prejudicar seu envolvimento com atividades de divulgação da ciência para o público geral. Durante as entrevistas de aprofundamento, alguns cientistas declararam dar preferência para a divulgação para pares por motivos diversos. Entre eles, podemos citar a ausência de uma cultura no Instituto que estimule a divulgação para leigos, a falta de tempo e a dificuldade de utilizar uma linguagem acessível. O depoimento a seguir, por exemplo, revela por que um dos entrevistados não tinha costume de se envolver com atividades de divulgação da ciência para o público geral: "Não dá tempo! Não tenho. O que eu faço é isso aqui. Publicação para os pares, internacionais, revistas de impacto, essas coisas.” (Cientista 4, 2016)

Apesar do valor dado à comunicação dos resultados para seus semelhantes, os cientistas do IOC também demonstraram interesse e envolvimento com a divulgação científica. Como exemplo disso, podemos citar a participação ativa de $54,3 \%$ dos pesquisadores que responderam ao questionário online em um evento para o público geral, como conferência, mesa-redonda, exposição de ciência, festival de ciência, Semana da Ciência ou Café Científico. O depoimento a seguir, concedido por Elisa Cupolillo, vice-diretora de Ensino, Informação e Comunicação do IOC, destaca de forma positiva o envolvimento do Instituto com a divulgação da ciência. Além disso, a pesquisadora, que assume um importante cargo de gestão, compartilha alguns dos esforços que têm sido feitos em relação a esse tipo de iniciativa: 
A divulgação sempre esteve presente, sim, no IOC. [...] Então assim, muitos pesquisadores do IOC, que tinham muito esse viés da comunicação de falar pro público e tudo, isso é uma coisa que tem, que continua, muita gente faz isso. Gosta, faz porque gosta, porque tá na natureza da pessoa mesmo.

É, a gente tem tentado estimular alguns veículos que existiam, mas não eram formais, não eram veículos formais. Então assim, simples, 'Fiocruz pra você', Semana Nacional de Ciência e Tecnologia, era feito assim: 'Quem quer participar?', e parava por aí. Hoje a gente tenta dar estímulos. E o que a gente está usando como veículo para esse estímulo: pós-graduação. Os alunos de pós-graduação, tentar inserir esses alunos nessas atividades. Porque a gente acredita, primeiro, que eles serão os futuros cientistas, segundo, que, para a formação de um aluno, é muito importante. Ele começar desde cedo essa atividade é muito mais fácil do que você pegar hoje um pesquisador consolidado e tal e, de repente, começar a fazer uma coisa que não era da natureza dele, que ele não aprendeu a fazer. Então, a gente tá trabalhando muito essas iniciativas com o 'Fiocruz pra você' e com a Semana Nacional de Ciência e Tecnologia. (Elisa Cupolillo, 2015)

Os eventos "Fiocruz pra você" e "Semana Nacional de Ciência e Tecnologia (SNCT)", citados no depoimento anterior, realmente foram bastante lembrados nas entrevistas de aprofundamento. No total, nove entrevistados fizeram menção a, pelo menos, uma dessas iniciativas. O primeiro é organizado pela presidência da Fiocruz ${ }^{32}$ e busca uma aproximação do público durante as campanhas de vacinação, por meio da promoção de feira de ciências, de atividades culturais e de lazer. Já a SNCT ${ }^{33}$ é uma iniciativa do governo federal, que incentiva a organização anual de eventos de divulgação científica em centenas de instituições do país durante o mês de outubro.

Porém, as atividades de divulgação científica que dependem de iniciativa própria e envolvem a publicação de conteúdo científico, tanto na mídia impressa quanto na online, apresentam menor participação dos pesquisadores que responderam ao questionário online. Uma grande parcela $(76,7 \%)$ disse que nunca escreveu um artigo sobre sua especialidade para um jornal, uma revista ou um site de notícias como autor convidado. Além disso, apesar de ser alta a porcentagem de pesquisadores $(87,4 \%)$ que declararam fazer parte de redes sociais para manter contato com família e amigos, ou se informar sobre questões políticas, culturais e científicas, poucos aproveitam esse espaço para compartilhar seu trabalho com o público.

Por exemplo, a maioria dos respondentes do questionário indicou que, no último ano, nunca colocou informação relacionada à sua pesquisa em um site, blog ou rede social destinada ao público geral $(86,4 \%)$. Outra parcela considerável (75,7\%) apontou que não colocou vídeo, foto ou áudio relacionado a seu trabalho em algum site de compartilhamento de mídias. Por fim, mais da metade dos participantes $(68,0 \%)$ declarou que jamais contribuiu na elaboração de um artigo em alguma enciclopédia online para o público geral.

Também foi reduzido o número de cientistas que declararam utilizar blogs para disponibilizar conteúdos científicos ou ter acesso a informações sobre ciência. Em relação ao uso ativo de blogs, que envolve moderação e produção de textos, a grande maioria dos pesquisadores do IOC que respondeu ao questionário online (94,2\%) indicou que não realiza esse tipo de atividade. Logo, somente $5,8 \%$ dos participantes declararam utilizar blogs de forma ativa. Já em relação ao uso passivo de blogs, percebemos um maior engajamento por parte dos cientistas, já que 26,2\% afirmaram que realizam leitura frequente de postagens de outros autores nesse tipo de site.

Dentre os motivos que contribuem para esse envolvimento pouco significativo dos cientistas do IOC com blogs, durante as entrevistas foram citados, como alguns dos obstáculos enfrentados pelos pesquisadores do Instituto, a falta de tempo, a pouca intimidade com informática e a falta de preparo para produzir textos de divulgação científica. Isso tudo acaba dificultando que eles comuniquem sua pesquisa diretamente para o público leigo por meio da internet, mas também destaca e valoriza a importância do trabalho dos jornalistas e dos meios de comunicação de massa na realização dessa tarefa.

Esse comportamento de pouco engajamento por parte dos cientistas com a divulgação científica por meio da internet não é um fenômeno restrito ao IOC. De maneira semelhante, cientistas participantes da investigação nacional ${ }^{17}$ demonstraram, em sua maioria, não utilizar blogs e redes sociais para falar de 
temas científicos com o público leigo, mesmo que 73,0\% dos respondentes se declarem membros de alguma rede social online. Os autores dessa investigação apontam que, de acordo com o relatório da Agência de Marketing Digital 360i34, o Brasil se destaca como um dos países da América do Sul com maior quantidade de adeptos ao uso de redes sociais. Em 2014, cerca de 79,0\% dos usuários da internet do país estavam ativos em alguma plataforma dessa natureza, porcentagem semelhante ao que é observado nos Estados Unidos. Dessa forma, Massarani e Peters ${ }^{17}$ discutem que, ao participarem de redes sociais, mas não utilizarem esse recurso para falar de ciência, os cientistas brasileiros podem estar perdendo uma boa oportunidade de se comunicar diretamente com o público.

Sobre esse tema, Brossard ${ }^{35}$ aponta que, atualmente, buscar um melhor entendimento sobre como o ambiente online tem afetado a comunicação das informações científicas para o público tornou-se uma necessidade. Novas realidades trazidas à tona pelos meios virtuais estão forçando cientistas e sociólogos a repensarem sobre essa interface entre a comunidade científica e o público. Entre as áreas afetadas por essa revolução, os autores citam as alterações na dinâmica do jornalismo científico, a utilização de algoritmos e coleta de dados para direcionar o consumo de informações dos internautas e o espaço de compartilhamento proporcionado pela web 2.0.

Por fim, nosso estudo buscou investigar detalhes sobre a comunicação entre os cientistas do IOC e o público. Não só no Instituto, mas também no Brasil ${ }^{17}$, a maior parte dos cientistas participantes discordou da afirmativa que diz que "a capacidade do público para fazer julgamentos é suficiente para permitir que participe na tomada de decisões em política científica”. Os resultados também foram similares no quesito em que os respondentes de ambas as investigações acreditam fortemente que quanto mais acesso ao conhecimento científico por parte do público, mais positiva será sua atitude diante da C\&T, o que pode resultar em visibilidade pública e apoio político.

Sobre esse tema, a realização de pesquisas de percepção pública permite traçar um perfil que ajude a compreender não só o acesso, mas também as atitudes da população em relação à informação científica. Por exemplo, em análise feita por Castelfranchi e colaboradores $36^{6}$ sobre a percepção de brasileiros constatou-se que a maioria possui uma visão otimista e apoiadora em relação à ciência. Porém, essa atitude não apresenta, necessariamente, uma relação direta com maior grau de instrução ou informação sobre C\&T. Assim, de acordo com os dados coletados na pesquisa realizada no IOC, percebemos que os cientistas do Instituto reconhecem o interesse do público brasileiro, porém também apontam que é preciso comunicar de uma forma acessível e contextualizada para que ele seja capaz de compreender os conteúdos científicos transmitidos.

\section{Considerações finais}

Neste artigo, por meio de um questionário online e de entrevistas de aprofundamento, buscamos investigar como se dá o relacionamento dos cientistas do IOC com os meios de comunicação de massa e com a divulgação científica em geral, seja por atividades institucionais ou individuais, pela internet ou presenciais. Apesar dos resultados se estenderem apenas à parcela de pesquisadores que participaram do estudo, eles mostram tendências relevantes da interação que ocorre entre a comunidade científica do Instituto e a mídia. Entre as que mais se destacam podemos citar o envolvimento considerável dos pesquisadores com os meios de comunicação de massa. Além disso, os dados indicam o estabelecimento de uma relação amigável e de confiança entre os cientistas do IOC e os jornalistas, tanto os ligados ao Sejor/ IOC, quanto os da imprensa em geral.

Algumas pesquisas realizadas nos últimos dez $\operatorname{anos}^{1,22.24,29,37}$ têm apontado que as interações entre ciência e mídia ocorrem de forma mais frequente e amigável do que costuma ser reproduzido pelo senso comum e do que foi observado em investigações mais antigas, como no relatório sobre a conturbada relação entre cientistas e jornalistas americanos durante os anos 1990, publicado por Hartz e Chappell ${ }^{38}$. 
Da mesma forma, os dados apresentados neste artigo indicam que os contatos estabelecidos entre profissionais da imprensa e pesquisadores do IOC também contrariam o senso comum e ocorrem de forma constante e positiva, indicando a existência de uma aproximação entre esses profissionais em vez de conflitos e desentendimentos.

Entretanto, sobre o engajamento dos participantes na divulgação da ciência em geral, percebemos que ele pode ser considerado tímido e dependente de estímulos institucionais. Além do contato com a mídia e das iniciativas organizadas pelo próprio IOC, como a participação em feiras de ciência e visitas a escolas, observamos que os pesquisadores não apresentam forte envolvimento com outras possibilidades de comunicar a ciência para o público leigo. Por exemplo, pouquíssimos participantes deste estudo - tanto os que responderam ao questionário online, quanto os que concederam entrevistas - se envolveram com a autoria e edição de livros ou disponibilizaram algum conteúdo científico em qualquer plataforma da internet (blog, enciclopédia online ou YouTube, por exemplo) por conta própria.

O pouco engajamento dos cientistas do IOC na divulgação do conhecimento científico que produzem por meio da internet é um resultado que chama a atenção, já que os pesquisadores afirmam ser membros de redes sociais e utilizar diversos recursos online no desenvolvimento de suas pesquisas. A falta de tempo, de interesse e de familiaridade com a informática foram observados como alguns dos obstáculos para que os pesquisadores do Instituto divulguem suas pesquisas na internet. Entretanto, também é possível que isso seja consequência da falta de conhecimento do real impacto que a era digital produz no cotidiano da sociedade atual. As mudanças nas dinâmicas de produção, disponibilidade de informações e de acesso a elas são muito recentes e ainda não estão consolidadas. Dessa forma, não só para os cientistas do IOC, mas para outros profissionais ligados aos meios científico e jornalístico, como ainda é difícil ter noção do poder e do alcance da internet, também não é uma tarefa fácil se aventurar e se arriscar a utilizar os recursos que ela nos oferece para realizar a divulgação da ciência de uma forma eficiente.

Outra importante observação que fizemos a partir dos resultados são as características da divulgação científica que o IOC promove pelos meios de comunicação de massa. O Instituto, que apresenta relevância e credibilidade diante de questões de saúde pública, envolvendo pesquisas, diagnósticos e tratamentos, apresenta ações direcionadas e orientadas de acordo com a influência da mídia. É possível dizer que esta investigação revelou algumas evidências que comprovam essa estreita relação entre a ciência produzida no IOC e a mídia, o que poderia ter ligação com as teorias de midialização e midiatização da ciência.

Entre essas evidências, podemos citar, mais uma vez, a considerável frequência de contato observada entre os cientistas do Instituto e os meios de comunicação de massa. Acreditamos que esse comportamento é resultado não só das iniciativas de procura da mídia, mas também dos interesses diversos dos cientistas em divulgar seu trabalho e da influência da própria gestão em estimular o relacionamento dos pesquisadores com a imprensa. As entrevistas de aprofundamento com os gestores do IOC revelaram que, realmente, existe uma preocupação em utilizar os meios de comunicação de massa para estabelecer uma interação clara e direta com diferentes setores da sociedade. A própria existência de um serviço de comunicação como o Sejor/IOC, que busca profissionalizar o relacionamento com jornalistas externos, também evidencia que a dinâmica de produção e comunicação do conhecimento científico do Instituto recebe forte orientação da mídia.

Por fim, acreditamos que a execução deste projeto de pesquisa foi de grande valor, uma vez que buscou estimular o envolvimento dos pesquisadores do Instituto - tanto os que participaram, quanto os que puderem ter acesso aos resultados - com a divulgação da ciência. Além disso, os resultados e desdobramentos desta investigação podem motivar a realização deste estudo com outras instituições de pesquisa. Essa iniciativa contribuiria para incentivar a busca de ações que possam fortalecer a divulgação da ciência produzida em outros campos do conhecimento, não se restringindo, apenas, à área das biociências e saúde. 


\section{Referências}

1. Field $\mathrm{H}$, Powell P. Public understanding of science versus public understanding of research. Public Underst Sci Nov. 2013;10(4):421-26.

2. Lewenstein BV. Science and media. In: Smelser NJ, Baltes PB. International Encyclopedia of the Social and Behavioral Sciences. Pergamon: Oxford; 2001:13654-57.

3. Weingart P. Science and the media. Res Policy. 1998. 27(8):869-79.

4. Peters HP, Heinrichs $H$, Jung A, Kallfall M, Petersen I. Medialization of science as a prerequisite of its legitimization and political relevance. In: Cheng D, Claessens M, Gascoigne NRJ, Metcalfe J, Schiele B, Shi S, editors. Communicating science in social contexts. New models, new practices. Springer: Amsterdam; 2008:71-92.

5. Hjarvard S. Midiatização: teorizando a mídia como agente de mudança social e cultural. Matrizes. jan./ jun. 2012;5(2):53-91.

6. Potter, WJ. Synthesizing a working definition of "mass" media. Review of Communication Research. 2013;1(1):1-30.

7. Peters HP, Dunwoody S, Allgaier J, Lo YY, Brossard D. Public communication of science 2.0: is the communication of science via the new media online a genuine transformation or old wine in new bottles? EMBO Rep. Jul 2014;15(7):731-815.

8. Flores GB. Entre a ciência e a mídia: um olhar de assessoria de imprensa. R Cient Ci Curso. jul./dez. 2012;1(1):43-8.

9. Conheça o IOC [Internet]. Rio de Janeiro: Instituto Oswaldo Cruz; 2016 [citado em 2017 jun. 28 ]. Disponível em: http://www.fiocruz.br/ioc

10. Câmara dos Deputados (BR). Decreto no 66.624, de 22 de maio de 1970. Dispõe sobre a Fundação Instituto Osvaldo Cruz [Internet]. DOU, Seção 1. 1970 maio 5 - [citado em 2017 jun. 28]. Disponível em: https://goo.gl/uFUcMs

11. Gadelha P, Palma AM. Memória: um século de pesquisa voltada para a saúde pública. Ci Hoje. 2000;157:77-9.

12. Instituto Oswaldo Cruz. Relatório científico 2015 [Internet]. Rio de Janeiro; 2016 [citado em 2017 jun. 28]. Disponível em: http://www.fiocruz.br/ioc/media/IOC2015 RelatorioLabs 2.pdf

13. Instituto Oswaldo Cruz. Guia do aluno: edição 2016 [Internet]. Rio de Janeiro; 2016 - [citado em 2017 jun. 28]. Disponível em: http://www.fiocruz.br/ioc/media/Guia Online (5).22.02.pdf

14. Instituto Oswaldo Cruz. Relatório de atividades 2013-2014 [Internet]. Rio de Janeiro; 2014 [citado em 2017 jun. 28]. Disponível em: https://goo.gl/xT6puF

15. Instituto Oswaldo Cruz. Confira as contribuições científicas do Instituto Oswaldo Cruz relacionadas ao vírus Zika em 2016 [Internet]. Rio de Janeiro; 2016 [citado em 2017 jun. 28]. Disponível em: https:// goo.gl/RQAkcx

16. Instituto Oswaldo Cruz. Vírus Zika identificado no líquido amniótico de gestante do Brasil é semelhante a linhagem que circulou na Polinésia Francesa [Internet]. Rio de Janeiro; 2016 [citado em 2017 jun. 28]. Disponível em: https://goo.gl/QJbbeh

17. Massarani L, Peters HP. Scientists in the public sphere: interactions of scientists and journalists in Brazil. An Acad Bras Ci. 2016;88(2):1165-75.

18. Instituto Oswaldo Cruz [Internet]. Rio de Janeiro; 2017 [citado em 2017 jun. 28]. Disponível em: http://www.fiocruz.br/ioc/cgi/cgilua.exe/sys/start.htm?tpl=home

19. Instituto Oswaldo Cruz. Laboratórios [Internet]. Rio de Janeiro; 2017 [citado em 2017 jun. 28]. Disponível em: http://www.fiocruz.br/ioc/cgi/cgilua.exe/sys/start.htm?sid=71

20. Instituto Oswaldo Cruz. Webmail institucional [Internet]. Rio de Janeiro; 2017 [citado em 2017 fev. 13]. Disponível em: http://correio.ioc.fiocruz.br/

21. Instituto Oswaldo Cruz. Contatos do webmail IOC [Internet]. Rio de Janeiro; 2017 [citado em 2017 fev. 13]. Disponível em: http://correio.ioc.fiocruz.br/? task=addressbook 
22. Peters HP, Brossard D, De Cheveigné S, Dunwoody S, Kallfass M, Miller S, Tsuchida S. Interactions with the mass media. Science. Jul. 2008;321:204-05.

23. Peters HP. Gap between science and the media revisited: scientists as public communicators. Proc Natl Acad Sci. Aug. 2013;110(suppl. 3):14102-09.

24. Allgaier J, Dunwoody S, Brossard D, Lo YY, Peters HP. Journalism and social media as means of observing the contexts of science. BioScience. Apr. 2013;63(4):284-7.

25. Formulários Google [Internet]. Mountain View: Google Inc; 2017 [citado em 2017 jun. 28]. Disponível em: https://www.google.com/intl/pt-BR/forms/about/

26. Bausela E. SPSS: un instrumento de análisis de datos cuantitativas. R Inform Edu Medios Audiovis. 2005;2(4):62-9.

27. Alves Z, Silva M. Análise qualitativa de dados de entrevista: uma proposta. Paidéia. 1992;2:61-9.

28. Dunwoody S, Scott B. Scientists as mass media sources. Journalism Quart; 1982;59:52-59.

29. Nielsen K, Kjaer CR, Dahlgaard J. Scientists and science communication: a Danish survey. J Sci Commun. 2007;6(1):1-12.

30. Petersen I, Heinrichs H, Peters HP. Mass-mediated expertise as informal policy advice. Sci Technol Human Values. 2010;35(6):865-87.

31. Peters HP, Brossard D, De Cheveigné S, Dunwoody S, Kallfass M, Miller S, Tsuchida S. Science-media interface: It's time to reconsider. Sci Commun. 2008;30(2):266-76.

32. Fundação Oswaldo Cruz. Fiocruz para você [Internet]; Rio de Janeiro; 2017 [citado em 2017 jun. 28]. Disponível em: https://portal.fiocruz.br/pt-br/content/fiocruz-pra-voce

33. Ministério da Ciência, Tecnologia, Inovações e Comunicações (BR); Semana Nacional de Ciência e Tecnologia (SNCT) [Internet]. Brasília; 2016 [citado em 2017 jun. 28]. Disponível em: http://semanact. mcti.gov.br/a-semana

34. 360i Report: global Twitter trends: Brazil [Internet]. Nova York: 360i Digital Marketing Agency; 2014 [citado em 2017 jun. 28]. Disponível em: https://goo.gl/pczsqc

35. Brossard D. New media landscapes and the science information consumer. Proc Natl Acad Sci. 2013;110(3):14096-101.

36. Castelfranchi Y, Vilela E, Lima L, Moreira I, Massarani L. As opiniões dos brasileiros sobre ciência e tecnologia: o 'paradoxo' da relação entre informação e atitudes. Hist Ci Saude-Manguinhos. nov. 2013;20(supl.):1163-83.

37. Dijkstra AM, Roefs MM, Drossaert CHC. The science-media interaction in biomedical research in the Netherlands. Opinions of scientists and journalists on the science-media relationship. J Sci Commun. $2015 ; 14(2): 1-21$.

38. Hartz J, Chappell R. Worlds apart: how the distance between science and journalism threatens America's future. Nashville: First Amendment; 1997. 